\title{
Senior Citizens Expressing Acute Mental Symptoms: Urgent Need for Support and Treatment is Not Identified in the Community
}

\author{
Kirsti Kähärä ${ }^{1 *}$, Jaakko Valvanne ${ }^{2}$, Juhani Grönlund³ ${ }^{3}$ Kari J Mattila ${ }^{4}$ \\ ${ }^{1}$ Suupohja Health Centre, Prännärintie 6-8, 61800 Kauhajoki, Finland \\ ${ }^{2}$ Department of Geriatric Medicine, University of Tampere, Lääkärinkatu 1, 33520 Tampere \\ ${ }^{3}$ Akaa Health Centre, Akaantie 2, 37800 Toijala \\ ${ }^{4}$ Centre of General Practice, Pirkanmaa Hospital District and University of Tampere. Lääkärinkatu 1, 33520 Tampere
}

\begin{abstract}
Background: The intention was to study the reactions to mental symptoms in older people in a rural community and assess how such people would obtain appropriate support in the local service system. Methods: A postal questionnaire study was conducted in the rural Suupohja area in Finland. The target groups were a randomized sample of residents aged 15-84 $(n=1200)$, local social and healthcare personnel $(n=463)$ and politicians $(n=148)$. The response rates were $45 \%, 61 \%$ and $55 \%$ respectively. A case of an elderly woman with mental symptoms was described. People were asked about alternatives in identifying the need for treatment as well as the urgency of the treatment and the location where the intervention should take place. Results: Of residents, $69 \%$, of politicians $76 \%$ and of health and social staff $76 \%$ recognized that elderly citizens needed urgent support and treatment. According to logistic regression, a significant association was found in the resident cohort between the need for urgent support and age over 50 years (OR 2.7). A total of 70\% of the inhabitants, $90 \%$ of the social and healthcare staff and $69 \%$ of the politicians estimated that appropriate care would be obtained in the home care unit. Conclusion: In this study, nearly onethird of the residents were found to be unaware of the urgent need for treatment of senior citizens. It is a challenge to increase the alertness and sensitivity of the population to recognize acute mental symptoms. The healthcare system should improve understanding and cooperation between the community, the healthcare professionals, and local politicians.
\end{abstract}

Keywords: Dementia, home care, mental health, access to care, acute mental symptom

\section{INTRODUCTION}

The aging of the population involves new challenges for the healthcare system and local social services in many countries. Mental symptoms in previously healthy elderly citizens cause confusion in the community. The co-existence of mental problems such as behavioural disorders, delusional symptoms or depression is very common in older people, especially those with dementia. In all societies, the prevalence of dementia is increasing. Among the population older than 65 years, the prevalence of memory symptoms is on average $5-9 \%$ and among older people above 85 more than $25 \%$ (Lobo et al., 2000; Ferri et al., 2005). Dementia is an important factor, but mental symptoms of senior citizens are multi-factorial, and symptoms occur also without dementia (Akincigil et al., 2011). The prevalence of depression as a mental disorder is high among older citizens who do not have memory diseases. According to epidemiologic studies in Finland, 16\% of women over 65 and 12\% of men over 65 suffer from mild or moderate depression (Pahkala et al., 1995). In addition, among the elderly, the prevalence of mental disorders related to somatic diseases is increasing (Perälä et al., 2007). Adverse drug events also create a risk in older people (Budnitz, Lovegrove, Shehab \& Richards, 2011; Salonoja et al., 2010). A senior citizen with delirium symptoms or acute confusion should have a comprehensive examination (O'Mahoney et al., 2011).

The early recognition and diagnosis of dementia, delirium or other mental symptoms is also important in any evaluation of the efficacy and cost-effectiveness of treatment (Suhonen et al., 2010; Getsios

*Correspondence regarding this article should be directed to: kirsti.kahara@1lky.fi et al., 2011; Weimer and Sager, 2009). The clinical role of mental disorders and dementia in the older people is especially prominent in that they affect quality of life and cause psychosocial impairment (Landreville, Voyer \& Carmichael, 2013).

In most cases, psychosocial support is provided by family members and the community. Society can offer psychosocial support to members with various symptoms of mental disorder if the need for help is recognized and the services are familiar. Many caregivers are themselves elderly citizens and their well-being should be improved through official services and primary healthcare (Raivio et al., 2007; Schoenmakers, Buntinx \& Delepeleire, 2009; Sigurdardottir, Sundström, Malmberg \& Bravell, 2012). A seamless chain of care and rehabilitation should be provided in a collaboration between primary healthcare, social services and specialized care. Cost-effectiveness can also be increased with effective co-operation among the services (Hill et al., 2002).

The national plan for mental health in Finland emphasizes the opinions of the patient and promotion of mental health and has its focus in primary and community care. Services should be available close to the individual environment (Ministry of Social Affairs and Health in Finland, 2010). In Finland the municipalities are responsible for organizing geriatric and mental health services. Recent studies have assessed how the organizational structure of healthcare systems may influence patients' attitudes to seeking care (Andersen et al., 2011). According to a recent Finnish study, mental health services for older people are scanty and knowledge on mental health problems of aged people varies (Pietilä \& Saarenheimo, 2010).

Our own district, Suupohja, developed a best practice model 
for local mental health services in 2004-2006 in order to improve the availability and functioning of mental health services (Kähärä, Piikkilä \& Mattila, 2008). The sensitivity of the population to mental symptoms in senior citizens has hitherto not been studied. Also, the rural population is an understudied and research-naïve population. The aim of our study was to chart the reactions and opinions of the general population, professionals in healthcare and social services, and local politicians in respect of symptoms in an elderly citizen with mental symptoms. A further objective was to establish how this old person would obtain appropriate support in the local healthcare and social services system.

\section{MATERIAL AND METHODS}

Our study was carried out in the rural Suupohja area of South Ostrobothnia in Finland (population 29,051). Suupohja is a rather large area (about 3150 square kilometers) with a residential density of 9.7 people per square kilometre. Its main manufacturing industries are industrial materials, the furniture industry and small-scale food processing. In agriculture, the main areas are potato, milk and meat production. The questionnaire was sent to three target groups: a randomized sample of inhabitants aged 15-84 $(n=1200)$, social and healthcare personnel in primary healthcare $(n=463)$ and local politicians $(n=148)$. A reminder letter was sent to groups who had not responded according to the postal register. Completed questionnaires were obtained from 893 persons (50.5\%).

\section{Resident Sample}

For the survey, a random sample of inhabitants living in the Suupohja area was drawn from the national population register. The original sample of inhabitants included 14 social and healthcare workers and six politicians who were ultimately excluded from the group. The final size of the resident group was 1180 persons. The total response rate was $45.4 \%(n=530)$. Of respondents, $61 \%$ were female. The younger the inhabitants were, the less they were likely to respond to this questionnaire. In the youngest age groups (born 1971-1993), the response rate was $30.6 \%$. The mean age of respondents was 53 . Of the total, $68 \%$ lived in a permanent relationship; $75 \%$ had children, 2.6 on average (Table 1).

\section{Local Politician Sample}

The responding local politicians were members of local municipal councils, municipal boards and committees responsible for social and health services. The response rate of the local politicians was $55.4 \%(\mathrm{n}=79)$. The mean age of the respondents was 52 , and $59 \%$ were male (Table 1).

\section{Social and Health Care Worker Sample}

The social and healthcare personnel were working in health centres, guidance centres, the social work sector, the day care sector, occupational healthcare and home nursing. The total response rate in this group was $61.3 \%(\mathrm{n}=284)$, and the mean age was 49 years. These workers were almost all female (Table 1).

\section{The Questionnaire}

In the questionnaire, respondents were asked to choose alternatives in to how to identify the need for treatment and support as well as the urgency of treatment. The persons envisaged had the kind of symptoms assumed to be typical in consultations of experienced general practitioners (GP) in this area. In respect of the problems of senior citizens, the hypothesis was that urgent intervention was needed and the best approach to the problem would be to contact the home care unit because home care staff are accustomed to the problems older people have and may make a home visit in order to assess the situation. The specific question in the questionnaire
Table 1.

Respondents to the questionnaire in the Suupohja area in South Ostrobothnia. Background variables of the respondents in different groups

\begin{tabular}{|c|c|c|c|}
\hline & Residents & $\begin{array}{l}\text { Social and } \\
\text { healthcare staff }\end{array}$ & $\begin{array}{c}\text { Local } \\
\text { politicians }\end{array}$ \\
\hline & $\begin{array}{c}n=530 \\
\%\end{array}$ & $\begin{array}{c}\mathrm{n}=\mathbf{2 8 4} \\
\%\end{array}$ & $\begin{array}{c}\mathrm{n}=79 \\
\%\end{array}$ \\
\hline \multicolumn{4}{|l|}{ Gender } \\
\hline Female & 61 & 98 & 41 \\
\hline Male & 39 & 2 & 59 \\
\hline \multicolumn{4}{|l|}{ Age } \\
\hline Under 40 & 23 & 19 & 17 \\
\hline $40-64$ & 50 & 80 & 70 \\
\hline Over 64 & 27 & 1 & 13 \\
\hline \multicolumn{4}{|l|}{ Marital status } \\
\hline Married or cohabiting & 68 & 87 & 86 \\
\hline Single & 32 & 13 & 14 \\
\hline \multicolumn{4}{|c|}{ Educational background } \\
\hline $\begin{array}{l}\text { Higher vocational or } \\
\text { university }\end{array}$ & 10 & 26 & 21 \\
\hline Lower vocational & 61 & 73 & 73 \\
\hline None & 29 & 1 & 6 \\
\hline
\end{tabular}

was, "An older woman is living alone next door to you. She has no relatives nearby; her only daughter is living in Helsinki (nearly 400 $\mathrm{km}$ away). In recent months, her behaviour has changed significantly. She stays awake at night, and she is also disturbingly noisy during the night. She does not greet her neighbours or walk outside her home any more. She has not emptied her mailbox for weeks. How do you evaluate the situation?"

With regard to the urgency of treatment, the statement was, "In my opinion these symptoms need urgent treatment." The alternatives were on a five-level Likert scale: "I totally agree/I slightly agree/I cannot say/I slightly disagree/I totally disagree. The respondent was also asked to estimate what he/she would do personally and in which sector of local healthcare or social services system the support and treatment of the elderly citizen would be obtained. The answer alternatives were "Yes" or "No". The background variables of the respondent were age, marital status, vocational education, employment status and number of children.

\section{Statistical Analysis}

Data were analysed using SPSS 16.0 for Mac OS X. Groups were compared using Pearson's chi-square test. Associations in evaluating the urgency of treatment by measuring the odds ratio $(\mathrm{OR})$ and its $95 \%$ confidence interval $(95 \% \mathrm{CI})$ were studied using logistic regression analysis. Before the analysis, the answer alternatives were re-modelled into two-level form (I totally agree/ versus other alternatives). Also age, marital status, vocational education, employment status and number of children were placed in two-level classes (under or over 50 years of age/married or cohabiting vs single/high vocational education or university degree vs low vocational education or none/ children vs no children).

The Ethics Committee of the South Ostrobothnia hospital district approved the study.

\section{RESULTS}

A total of $69 \%$ of the inhabitants, $76 \%$ of the local politicians and $76 \%$ of the health and social workers felt that the older woman in the questionnaire needed urgent support and treatment. In logistic regression analysis among the resident sample, a statistically significant positive association was found between the need for urgent support and the respondent's age of more than 50 years (Table 2). Inhabitants over 50 felt that urgent intervention was 
needed more than their younger peers. Female respondents tended to show more concern than male, but the difference was not statistically significant.

The actions the respondents were ready to take are presented in (Table 3). In the matter of assistance to the older women, the most common answer was contacting the relatives. Approximately $90 \%$ of respondents in all groups suggested this approach. Resident respondents would personally assist the woman some ten per cent units less than local politicians and health and social staff. The local politicians and professionals relied more on the health and social sector than residents, the difference being 13-18 per cent.

The respondents suggested that appropriate care in the health and social sector would mostly be found in the home care unit or in the acute care unit of the health centre (Table 4). Among social and healthcare staff, it was proposed approximately 20 per cent units more often than in the other groups that appropriate care would be obtained in the home care unit. The acute care unit of the health centre would be an appropriate care-provider, according to $62-67 \%$ of the respondents.

\section{DISCUSSION}

Almost one-third of residents did not feel that urgent treatment was needed. Among the general population, inhabitants over 50 years of age showed more concern about the symptoms than the younger age groups. Among the local politicians and social and healthcare workers, one in four respondents did not recognize an urgent need for intervention.

Postal questionnaires involve a risk of selection, depending on

Table 2.

Responses: "In my opinion these symptoms urgently need treatment." Odds ratios in logistic regression analysis. The odds ratio and its $95 \%$ confidence interval is bolded when statistically significant

\begin{tabular}{|c|c|c|c|c|c|c|}
\hline & \multicolumn{2}{|c|}{ Residents } & \multicolumn{2}{|c|}{ Politicians } & \multicolumn{2}{|c|}{$\begin{array}{c}\text { Social and } \\
\text { healthcare staff }\end{array}$} \\
\hline & OR & $95 \% \mathrm{Cl}$ & OR & $95 \% \mathrm{Cl}$ & OR & $95 \% \mathrm{Cl}$ \\
\hline \multicolumn{7}{|l|}{ Gender } \\
\hline Male & 1 & & 1 & & 1 & \\
\hline Female & 1.40 & $0.92-1.13$ & 2.13 & $0.62-7.32$ & 2.17 & $0.43-10.88$ \\
\hline \multicolumn{7}{|l|}{ Age } \\
\hline Under 50 & 1 & & 1 & & 1 & \\
\hline$\geq 50$ & 2.70 & $1.75-4.17$ & 2.99 & $0.91-9.85$ & 0.86 & $0.47-1.55$ \\
\hline \multicolumn{7}{|c|}{ Marital status } \\
\hline Single & 1 & & 1 & & 1 & \\
\hline Other & 1.03 & $0.62-1.71$ & 1.12 & $0.14-8.72$ & 0.56 & $0.21-1.45$ \\
\hline \multicolumn{7}{|l|}{ Education } \\
\hline Higher & 1 & & 1 & & 1 & \\
\hline $\begin{array}{l}\text { Lower or } \\
\text { none }\end{array}$ & 0.99 & $0.63-2.43$ & 3.51 & $\begin{array}{l}0.91- \\
13.49\end{array}$ & 1.12 & $0.59-2.31$ \\
\hline \multicolumn{7}{|c|}{ Number of children } \\
\hline None & 1 & & 1 & & 1 & \\
\hline One or more & 1.52 & $0.88-2.62$ & 0.37 & $0.04-3.52$ & 1.34 & $0.51-3.53$ \\
\hline
\end{tabular}

Table 3.

The actions respondents would take to assist the older woman with mental symptoms. The alternatives were "yes" or "no". Proportion of "yes" answers

\begin{tabular}{|l|c|c|c|}
\hline & Residents & $\begin{array}{c}\text { Social and } \\
\text { healthcare staff }\end{array}$ & $\begin{array}{c}\text { Local } \\
\text { politicians }\end{array}$ \\
\cline { 2 - 4 } & $\begin{array}{c}\mathbf{n = 5 3 0} \\
\mathbf{\%}\end{array}$ & $\begin{array}{c}\mathbf{n = 2 8 4} \\
\mathbf{\%}\end{array}$ & $\begin{array}{c}\mathbf{n = 7 9} \\
\mathbf{\%}\end{array}$ \\
\hline $\begin{array}{l}\text { I would personally help } \\
\text { the woman. }\end{array}$ & 51 & 62 & 63 \\
\hline $\begin{array}{l}\text { I would contact the } \\
\text { woman's relatives. }\end{array}$ & 87 & 92 & 89 \\
\hline $\begin{array}{l}\text { I would contact the } \\
\text { health and social sector. }\end{array}$ & 73 & 86 & 91 \\
\hline
\end{tabular}

Table 4

The opinions of respondents as to where the appropriate care would be obtained in the local health and social sector. The alternatives were the acute care unit of the health centre, the home care unit, the family guidance centre, the guidance centre for memory diseases, the social work unit or the team for psychosocial support. Proportion of "yes" answers

\begin{tabular}{|c|c|c|c|}
\hline & Residents & $\begin{array}{c}\text { Social and } \\
\text { healthcare staff }\end{array}$ & $\begin{array}{c}\text { Local } \\
\text { politicians }\end{array}$ \\
\hline & $\begin{array}{c}n=530 \\
\%\end{array}$ & $\begin{array}{c}n=284 \\
\%\end{array}$ & $\begin{array}{c}n=79 \\
\%\end{array}$ \\
\hline Acute care unit & 62 & 65 & 67 \\
\hline Home care unit & 70 & 90 & 69 \\
\hline $\begin{array}{l}\text { Family guidance } \\
\text { centre }\end{array}$ & 30 & 46 & 43 \\
\hline $\begin{array}{l}\text { Guidance centre } \\
\text { for memory } \\
\text { diseases }\end{array}$ & 22 & 32 & 16 \\
\hline Social work unit & 63 & 62 & 61 \\
\hline $\begin{array}{l}\text { Team for } \\
\text { psychosocial } \\
\text { support }\end{array}$ & 13 & 11 & 30 \\
\hline
\end{tabular}

the responses received. The response rate in the samples varied between groups. The rural population is an understudied group and difficult to reach: their response rate was within a range comparable to that found in previous studies among politicians (Eronen et al., 2014), employees (Midttun, 2007; Haukilahti et al., 2008) and general population (Tuulari, Aromaa, Herberts \& Wahlbeck, 2007). Our findings accord with those of previous studies in which the response rate was higher among female respondents and respondents of older age than among male respondents and in younger age groups. The questionnaire was laborious for the respondents. A limitation of the research was that it was not possible to analyse the non-responding groups compared with the responding groups: for example, was there a difference in mean age, marital status or education. In the questionnaire, the description of the symptoms of the senior citizen was in narrative form in order to elicit the attitudes of the respondents. Clinical scenarios have been widely used in the education of healthcare professionals in assessing decisions made by professionals (Moskowitz, Kuipers \& Kassirer, 1988; Sedgwick, Grigg \& Dersch, 2014) and also in studying the diversity of physicians' behaviour (Hinkka, 2001). A clinical scenario of an elderly woman was chosen in our questionnaire because experienced general practitioners in the area estimated that this scenario represented a highly typical consultation. The life expectancy of women is approximately six years longer than the life expectancy of men (Findicator, 2016). Many elderly women live alone after their spouse has died; they are often vulnerable and suffer from loneliness.

The questionnaire was also sent to local politicians. In a democracy, the opinion of the population should have an impact on the decisions of politicians when, for example, the municipality is developing the service sector of primary healthcare and social services. Funding and resources for the healthcare system depend on political decisions. At the same time, the quality of treatment has to be followed on regional and national levels. The health and social sector personnel and politicians approached in our study identified the urgent need for support and treatment in the case of the older woman more often than the general population.

The results showed a good sense of community. Of the responding area residents, $87 \%$ would contact the woman's relatives. A sense of community is highly valuable in a community and has broadly positive effects on mental health (Cook, Herman, Phillips $\&$ Sttersten, 2002). The inhabitants under 50 showed less concern with the symptoms than the older age groups. This may indicate that the older age groups have a stronger sense of community than the younger groups. On the other hand, most caregiving family members are themselves elderly persons, and this leads to more sensitivity in assessing different symptoms of a person. 
The home care unit of the local health centre was regarded as the most appropriate place to obtain help, and the health centre acute care unit was considered second best. Home care units play an important role in local services, as they are located in the area. Other primary healthcare and social services are concentrated in the central areas of the Suupohja municipalities. The home care units rely on the social capital (Falk \& Kilpatrick, 2000) of the community. The older generation has usually lived their whole life in the district and depended on the voluntary help of the community and neighbors in their everyday life. According to the results of the questionnaire, the respondents in all groups were active in themselves contacting the relatives of senior citizens. Higher levels of networks, civic participation and cohesion have been reported in rural versus urban areas (Ziersch et al, 2009).

When the local best-practice model for mental health services (Kähärä, Piikkilä \& Mattila, 2008) was designed, social and healthcare personnel were trained to use the model in advising patients how to obtain treatment. In this model, the treatment and care of senior citizens was coordinated from the local home care units, as may be observed from the results of our questionnaire study. The coordinative role of the home care unit was widely recognized by social and healthcare professionals. Familiarity with home care services was lower among residents and local politicians. In many healthcare systems, general practitioners work as gatekeepers to specialists and medical resources (Forrest, 2003). Making the local services known to the inhabitants should be a major task for general practitioners, nurses and social workers.

In ensuring quality of life for older people, it is of the utmost importance that memory diseases, mental symptoms and symptoms of delirium are recognized at an early stage and that their access to care is facilitated. Symptoms of delirium can have life-threatening consequences for older people if they are not recognized and treated appropriately (Han et al., 2009). There are recommendations for optimal practice in the treatment of progressive memory diseases. The appropriate services should be provided locally in a multiprofessional memory clinic whose responsibilities in the care of memory patients should be agreed upon within regional chains of care. A prerequisite of this is sufficient local resources (Suhonen et al., 2010).

\section{CONCLUSIONS}

The opinions and social attitudes of the community play a prominent role in reaching the goals of mental health strategies. A sense of community was identified in the responses of the local inhabitants. The access to health and social services is important, and special assistance is needed especially when the patient him-/ herself cannot fully comprehend the situation. It is a challenge to promote the necessary knowledge and sensitivity in the general population, especially the younger age groups, so they can recognize mental symptoms in older people. At the same time, provision of appropriate information regarding local services is a shared task within the community. The social and healthcare system should improve understanding and cooperation between the community, healthcare professionals, and the local politicians.

\section{Conflict of Interest}

None.

\section{Description of Authors' Roles}

Kirsti Kähärä was responsible for the study conception and design, and performed the data collection and drafted the manuscript. Jaakko Valvanne and Juhani Grönlund made critical revisions to the study. Kari Mattila made critical revisions and supervised the study and the data collection. All authors approved the final version of the manuscript.

4 Kähärä, Valvanne, Grönlund \& Mattila • Senior Citizens Expressing Acute Mental Symptoms

\section{References}

Akincigil, A., Olfson, M., Walkup, J.T., Siegel, M.J., Kalay, E., Amin, S., et al. (2011). Diagnosis and treatment of depression in older community-dwelling adults: 1992-2005. Journal of the American Geriatrics Society, 59(6), pp. 1042-1051.

Andersen, R.S., Vedsted, P., Olesen, F., Bro, F. and Sondergaard, J. (2011). Does the organizational structure of health care systems influence care-seeking decisions? A qualitative analysis of Danish cancer patients' reflections on care-seeking. Scandinavian Journal of Primary Health Care, 29(3), pp. 144-149.

Budnitz, D.S., Lovegrove, M.C., Shehab, N. and Richards, C.L. (2011). Emergency hospitalizations for adverse drug events in older Americans. The New England Journal of Medicine, 365(21), pp. 2002-2012.

Cook, T., Herman, M., Phillips, M. and Sttersten, R. (2002). Some ways in which neighborhoods, nuclear families, friendship groups, and schools jointly affect changes in early adolescent development. Child Development, 73(4), 1283-309.

Falk, I. and Kilpatrick, S. (2000). What is social capital? A study of interaction in a rural community. Sociologia Ruralis, 40, pp. 87-110.

Ferri, C., Prince, M., Brayne, C., Brodaty, H., Fratiglioni, L., Ganguli, M., et al. (2005). Alzheimer's disease International Global prevalence of dementia: A Delphi consensus study. Lancet 366, 2112-2117.

Getsios, D., Blume, S., Ishak, K.J., Maclaine, G. and Hernandez, L. (2012). An economic evaluation of early assessment for Alzheimer's disease in the United Kingdom. Alzheimer's \& dementia: The Journal of the Alzheimer's Association, 8(1), Pp. 22-30.

Eronen, A., Hakkarainen, T., Londen, P. and Peltosalmi, J. Sosiobarometer (2014) SOSTE, The Finnish Federation for Social Welfare and Health. Helsinki.

www.findikaattori.fi

Forrest, C. (2003). Primary care gatekeeping and referrals: effective filter or failed experiment? BMJ, 326(7391), 692-695.

Han, J.H., Zimmerman, E.E., Cutler, N., Schnelle, J., Morandi, A., Dittus, R.S., et al. (2009). Delirium in older emergency department patients: Recognition, risk factors, and psychomotor subtypes. Academic Emergency Medicine, 16(3), pp. 193-200.

Haukilahti, R-L., Virjo I., Halila H., Hyppölä H., Isokoski M., Kujala S., et al. (2008). Does physicians' work change - and in what direction. (In Finnish, abstract in English.) Suomen Lääkärilehti 5, pp. 405-41.

Hill, J.W., Futterman, R., Duttagupta, S., Mastey, V., Lloyd, J.R., Fillit, H. (2002). Alzheimer's disease and related dementias increase costs of comorbidities in managed Medicare. Neurology, 58(1), pp. 62-70.

Hinkka, H. (2001). Decision making in end of life care. Acta Universitatis Tamperensis 839. Tampere.

Kähärä, K., Piikkilä, S. and Mattila, K. ( 2008). The best practice model in local mental health services in Suupohja area. (In Finnish, abstract in English.) Suomen Lääkärilehti, 7, pp. 649653.

Landreville, P., Voyer, P. and Carmichael, P.H. (2013). Relationship between delirium and behavioral symptoms of dementia. International Psychogeriatrics / IPA, 25(4), pp. 635-643.

Lobo, A., Launer, L.J., Fratiglioni, L., Andersen, K., Di Carlo, A., Breteler, M.M., et al. (2000) Prevalence of dementia and major subtypes in Europe: A collaborative study of population-based cohorts. Neurologic Diseases in the Elderly Research Group. Neurology, 54 (11 Suppl 5), pp. S4-9. 
Midttun, L. (2007). Private or public? An empirical analysis of the importance of work values for work sector choice among Norwegian medical specialists. Social Sciences \& Medicine (1982), 64(6), pp. 1265-1277.

Ministry of Social Affairs and Health in Finland. (2010). Plan for mental health and substance abuse work. Proposals of the Mieli 2009 working group to develop mental health and substance abuse work until 2015. Helsinki.

Moskowitz, A., Kuipers, B. and Kassirer, J. (1988). Dealing with uncertaintity, risks and tradeoffs in clinical decisions: a cognitive science approach. Annals of Internal Medicine 108, 435-449.

O'Mahony, R., Murthy, L., Akunne, A., Young, J. and Guideline Development Group. (2011). Synopsis of the National Institute for Health and Clinical Excellence guideline for prevention of delirium. Annals of Internal Medicine, 154(11), pp. 746-751.

Pahkala, K., Kesti, E., Kongas-Saviaro, P., Laippaöa, P. and Kivela, S.L. (1995). Prevalence of depression in an aged population in Finland. Social Psychiatry and Psychiatric Epidemiology, 30(3), pp. 99-106.

Perala, J., Suvisaari, J., Saarni, S.I., Kuoppasalmi, K., Isometsa, E., Pirkola, S., et al. (2007). Lifetime prevalence of psychotic and bipolar I disorders in a general population. Archives of General Psychiatry, 64(1), pp. 19-28.

Pietilä, M. and Saarenheimo, M. (2010). Mental health of older people: public perceptions, aims and practices. Changing Minds research and development project, Research report 1. Central Union for the Welfare of the Aged in Finland.

Pitkälä, K.H., Laurila, J.V., Strandberg, T.E., Kautiainen, H., Sintonen, H., Tilvis, R.S. et al. (2008). Multicomponent geriatric intervention for elderly inpatients with delirium: effects on costs and health-related quality of life. The Journals Of Gerontology. Series A, Biological Sciences and Medical Sciences, 63(1), pp. 56-61.

Raivio, M., Eloniemi-Sulkava, U., Laakkonen, M.L., Saarenheimo, M., Pietila, M., Tilvis, R. et al. (2007). How do officially organized services meet the needs of elderly caregivers and their spouses with Alzheimer's disease? American Journal of Alzheimer's Disease and Other Dementias, 22(5), pp. 360-368.

Salonoja, M., Salminen, M., Aarnio, P., Vahlberg, T. and Kivelä, S.L. (2010). One-time counselling decreases the use of benzodiazepines and related drugs among community-dwelling older persons. Age and Ageing, 39(3), pp. 313-319.

Schoenmakers, B., Buntinx, F. and Delepeleire, J. (2009). What is the role of the general practitioner towards the family caregiver of a community-dwelling demented relative? A systematic literature review. Scandinavian Journal of Primary Health Care, 27(1), pp. 31-40.

Sedgwick, M., Grigg, L. and Dersch, S. (2014). Deepening the quality of clinical reasoning and decision-making in rural hospital nursing practice. Rural and Remote Health Journal. 14(3), 2858.

Sigurdardottir, S.H., Sundström, G., Malmberg, B. and Bravell, M.E. (2012). Needs and care of older people living at home in Iceland. Scandinavian Journal of Public Health, 40(1), pp. 1-9.

Suhonen, J., Pirttila, T., Erkinjuntti, T., Koponen, H., Makkonen, M., Puurunen, M. et al.(2010). Update on current care guidelines in Finland.

The diagnosis and medical treatment of memory disorders. Duodecim; Laaketieteellinen Aikakauskirja, 126(18), pp. 21672168.

Tuulari, J., Aromaa, E., Herberts, K. and Wahlbeck, K. (2007). Depression in Ostrobothnia and access to care. (In Finnish). Suomen Lääkärilehti, 8, pp. 790-791.

Weimer, D.L. and Sager, M.A. (2009). Early identification and treatment of Alzheimer's disease: social and fiscal outcomes. Alzheimer's \& dementia: The Journal of the Alzheimer's Association, 5(3), pp. 215-226.

Ziersch, A.M., Baum, F., Darmawan, I.G., Kavanagh, A.M. and Bentley, R.J. (2009). Social capital and health in rural and urban communities in South Australia. Australian and New Zealand Journal of Public Health, 33(1), pp. 7-16. 